\title{
MULHERES CAMPONESAS E O DIA 08 DE MARÇO NA LUTA DE CLASSES
}

Noeli Welter Taborda*

\begin{abstract}
Resumo
O presente ensaio traz um estudo sobre a origem e a importância do dia 08 de março, marco internacional de luta das mulheres trabalhadoras, sob a perspectiva de classe e de gênero. Com o objetivo de registrar elementos da ressignificação da data, este ensaio apresenta uma reflexão sobre a ação das mulheres, em especial das camponesas, através do Movimento de Mulheres Camponesas (MMC). Tal ressignificação apresenta o dia 08 de março como uma data de resistência, além da participação das mulheres camponesas nesse processo, a partir de propostas de mobilização construídas pelo MMC. A metodologia utilizada foi a de pesquisa participante, através dos instrumentos de observação, análise documental e bibliográfica, além da inserção e participação da autora no movimento.
\end{abstract}

Palavras-chave: Movimento de Mulheres Camponesas. 08 de março. Luta de classes.

* Militante do Movimento de Mulheres Camponesas (MMC/SC).Email: noe.welter@gmail.com 


\section{Introdução}

O presente texto traz um estudo sobre a origem e a importância do dia 08 de março, como marco internacional de luta das mulheres trabalhadoras, a partir de uma perspectiva de classe e de gênero. Apresenta-se uma reflexão sobre a ação das mulheres, em especial das camponesas, através do Movimento de Mulheres Camponesas (MMC). Com o objetivo de registrar elementos da ressignificação que as mulheres camponesas fazem a esta data, como um dia de resistência, se destaca a participação destas nesse processo, a partir das propostas de mobilização construídas pelo MMC. A metodologia utilizada foi a de pesquisa participante, com o uso de instrumentos de observação e a análise documental e bibliográfica, além da inserção e participação da autora no movimento.

Existem poucos registros históricos sobre a contribuição das camponesas nesse processo, por este motivo justifica-se a importância da escrita de suas contribuições. Para isso, as origens do Dia Internacional da Mulher são aqui contextualizadas, em busca de referências históricas da contribuição das mulheres camponesas na construção do 08 de março, como um dia de luta pelos seus direitos através da resistência de gênero e de classe.

\section{Origens do Dia Internacional da Mulher}

Para tratar sobre as origens do Dia Internacional da Mulher é preciso aprofundar e perceber como se estabeleciam as relações de gênero em meados do século XIX e início do século XX. Para tanto, partimos de tais questões: Qual era o papel da mulher e quais eram as formas de opressão às quais estavam submetidas? E como essas questões influenciaram para a organização na luta pela emancipação e direitos da mulher? Segundo Toledo (2001), o termo gênero surge para tratar questões referentes à opressão das mulheres enquanto uma construção social e permeada por relações de poder estabelecidas entre homens e mulheres, caracterizando os papéis que cada um assume na sociedade.

Pode-se afirmar que essas relações eram muito desiguais, sendo que as mulheres eram submetidas a uma dupla jornada de trabalho caracterizada pela opressão do homem sobre a mulher, bem como pela exploração de classe.

De acordo com as reflexões que Marx e Engels realizaram sobre a situação da mulher na sociedade e no sistema de produção cap-

REVISTA GRIFOS - N. 34/34 - 2013 
italista, devemos concluir que segundo sua doutrina marxista, a mulher estava submetida a uma dupla opressão. De um lado, estava subordinada à autoridade do marido dentro do casamento e, de outro lado sofria da mesma forma que os homens, a opressão exercida sobre todo o proletário pelos empresários capitalistas, embora que em um grau maior que os homens, já que chegavam a receber, pelo mesmo trabalho, até a metade do salário que recebia um homem (GONZALEZ, 2010, p.51-52).

Além das desigualdades destacadas, às mulheres era negado o direito de estudar, de herdar os bens da família, de participar de associações e sindicatos e o direito ao voto. No início do século XX as mulheres intensificaram a luta pelo direito de votar, pois acreditavam que alcançar tal direito seria um instrumento fundamental para a conquista dos demais direitos.

Em diversos países já existiam movimentos de mulheres por mudanças na legislação civil, em especial na regulamentação do casamento e do divórcio, pelo direito de frequentar escolas e exercer ofícios e profissões, de terem acesso à herança e aos bens da família, de participar de associações políticas e sindicais. Mas a reivindicação que mais se destacava e mobilizava era o direito ao voto, considerado um instrumento indispensável para que os demais direitos pudessem existir (FARIA, 2010, p. 9).

$\mathrm{Na}$ medida em que a propriedade privada foi se consolidando, a concentração das riquezas nas mãos de poucos se intensificou, bem como a divisão sexual do trabalho e o domínio do patriarcado ${ }^{1}$. A cultura patriarcal está tão impregnada na vida das mulheres que muitas acreditam ser natural a opressão, a violência e a exploração. Porém, o grande capital se beneficia desta desigualdade para concentrar mais riqueza ${ }^{2}$.

Junto com a divisão de classes pode-se dizer que a família patriarcal, onde o chefe é o homem, reforça a opressão da mulher,

A conexão entre a propriedade privada e a sujeição da mulher, deixa claro como num regime de propriedade privada é fundamental o controle cerrado das mulheres e de sua sexualidade. Por outro lado, isso intensifica a divisão sexual do trabalho: o trabalho produtivo da mulher concentra-se na produção de valores de uso e o do homem, nos valores de troca. Como há precedência da produção de valores de troca sobre a de valores de uso, a mulher passava a trabalhar para o marido e os filhos e o homem para a troca e a aquisição de propriedade, (TOLEDO, 2001, p. 18).
1Segundo Gebara (2002) o patriarcado é um sistema social onde o homem tem superioridade em relação à mulher e, com isso, as mulheres são submetidas a relações de

2 Salários menores são pagos às mulheres, sendo que além do trabalho nas indústrias com a dupla jornada de trabalho que as mulheres realizam, elas fazem o trabalho doméstico que não é remunerado,. 
De acordo com a mesma autora, as conclusões de Engels foram fundamentais para a compreensão de que a luta pela emancipação da mulher é uma luta contra o capitalismo e que enquanto esse sistema persistir, as mulheres continuarão sendo oprimidas e exploradas, devido à conexão intrínseca entre a propriedade privada dos meios de produção e o patriarcado. Neste sentido, a opressão da mulher está ligada às transformações sociais ocorridas desde as primeiras sociedades, ou seja, a mulher não nasceu oprimida.

Com esta reflexão, estamos querendo enfatizar que em função de vários fatores históricos, é consolidada uma forma de opressão específica caracterizada pela relação entre o patriarcado e o capitalismo. Tal relação é sustentada fortemente por uma superestrutura ideológica baseada em valores, costumes e crenças. Dessa forma, tal forma de opressão somente será superada quando houver uma profunda mudança na infraestrutura que possa romper com a sociedade privada e com a divisão de classes.

Foi na chamada primeira revolução industrial entre 1770 e 1830 na Inglaterra, que ocorreu a entrada de um significativo contingente de mulheres no mercado de trabalho. Esta introduziu a maquinaria no processo de produção de mercadorias e de concentração de um grande número de trabalhadores/as nas fábricas. Com a entrada das mulheres no mercado de trabalho uma nova forma de exploração de classe e de gênero se constituiu, na medida em que as mulheres realizavam o mesmo trabalho que os homens. Porém, o salário das mulheres, que não equivalia a $40 \%$ do salário pago aos homens, possibilitou ao capital aumentar seu lucro a partir de um custo muito menor (TOLEDO, 2001).

Neste contexto, se destaca também a introdução da máquina nas indústrias, que incorporou um número massivo de mulheres na classe operária, na medida em que a maquinaria permitia cada vez mais o emprego de trabalhadores sem força muscular, gerando a exploração da força de trabalho da mulher e da criança.

A maquinaria, ao tornar inútil a força do músculo, permite empregar trabalhadores sem força muscular ou sem um desenvolvimento físico completo, que possuem, no entanto, uma flexibilidade em seus membros. O trabalho da mulher e da criança foi, portanto, o primeiro grito da aplicação da maquinaria. Desse modo, aquele instrumento gigantesco para eliminar trabalho e operários, se convertia imediatamente em meio de multiplicação do número de assalariados, colocando todos os indivíduos da família operária 
sem distinção de idade ou sexo, sob a dependência imediata do capital. Os trabalhos forçados a serviço do capitalista invadiram e usurparam não só o lugar reservado às brincadeiras infantis, mas também o posto de trabalho livre dentro da esfera doméstica e a romper com as barreiras morais, invadindo a órbita reservada inclusive ao próprio lar (TOLEDO, 2001, p. 39).

Toledo (2001) nos permite refletir sobre a ideia sexista de que a mulher é considerada força de trabalho "inferior ou mais frágil”, somente quando a máquina é introduzida no mercado de trabalho. Isso nos parece muito contraditório, pois a mulher sempre desenvolveu trabalhos pesados como arar a terra, cuidar de animais, carregar filhos. Além disso, as mulheres camponesas são as responsáveis pela produção de alimentos saudáveis e diversificados, pelo cuidado com as sementes, com a terra, a água e o ar, e ao longo dos anos utilizam as plantas para curar, por se preocuparem com a vida das pessoas e do planeta.

Se por um lado as mulheres avançam na conquista de espaço no mundo do trabalho industrial, por outro a ideia de que o lugar ideal da mulher é ser dona de casa e ser mãe de família se reforçava.

A exploração capitalista não destrói a estrutura familiar, como inicialmente imaginaram os pensadores marxistas. E o movimento sindical predominantemente masculino, apoiou e reforçou o papel da família operária e o lugar ideal das mulheres como donas de casa e mães de família. A contradição entre reivindicações de melhoria das condições de trabalho muitas vezes se apoiou na restrição ao direito das mulheres ao trabalho, alimentando uma lógica de organização do mercado de trabalho, legitimada durante décadas, que considerava "natural" a demissão da mulher ao se casarem, ou a existência de profissões consideradas "adequadas" ao padrão de feminilidade imposto. São alguns mecanismos de controle da exploração dos trabalhadores em seu conjunto e das mulheres em particular, que favorecem aos trabalhadores do sexo masculino reforçando a desigualdade entre mulheres e homens (FARIA, 2010, p. 12-13).

Ao mesmo tempo em que se percebe a contradição entre reivindicações de melhoria das condições de trabalho e a restrição ao direito das mulheres ao trabalho neste contexto, reforçamse mecanismos de controle da exploração dos trabalhadores em seu conjunto e, em particular, das mulheres. Com o aumento da desigualdade entre homens e mulheres no mercado de trabalho, 
3 Ver a obra de Ana Isabel Álvarez González, $\quad 1^{\mathrm{a}}$ edição. Editora Expressão Popular. SOF - Sempreviva Organização Feminista. São Paulo. 2010

4. Ver Vito Giannotti, 8 de março de 2004 Memória - 8 de Março O Dia da Mulher nasceu das mulheres socialistas. Disponível em: <http://www piratininga.org.br $>$ surgem lutas para denunciar as péssimas condições laborais e a falta de segurança, trazendo graves problemas na vida das trabalhadoras e dos trabalhadores.

Essas contradições do passado trouxeram uma enorme necessidade de organização das mulheres para que as formas de exploração pudessem ser extinguidas. Porém, tais enfrentamentos trazem muitas tensões, inclusive dentro dos movimentos revolucionários, pois a entrada das mulheres no mercado de trabalho poder diminuir o número trabalhadores homens nas fábricas e, consequentemente, seus salários. Dependentes financeiramente dos maridos, às mulheres foi dada a responsabilidade da casa, da educação e do cuidado com os filhos e filhas. Assim, muitos homens não acreditavam e não valorizavam a capacidade das mulheres na organização e na luta contra o modelo capitalista e patriarcal.

Neste contexto nascem as lutas das mulheres por melhoria salarial, redução da jornada de trabalho, fim do trabalho infantil, direito a férias, proteção à maternidade, melhorias nas condições de trabalho contra a falta de segurança, direito ao voto, entre outros. Aos poucos as mulheres foram aprendendo que a garantia de direitos sociais e políticos exige a mudança da sociedade. É neste contexto de participação pela luta por direitos, voz e valorização da mulher que surge o Dia Internacional da Mulher Lutadora, o 08 de março.

Há uma polêmica gerada em torno do surgimento do Dia Internacional das Mulheres. Atribui-se a origem deste dia a memória da greve ocorrida em 1857 em Nova Iorque, onde morreram 129 operárias no incêndio ocasionado pelo patrão da fábrica em que trabalhavam. Curiosamente, não havia nada que documentasse esse fato, porém no livro recentemente lançado "As Origens e a Comemoração do Dia Internacional das Mulheres", é afirmado que este incêndio realmente aconteceu e se caracterizou como um fato trágico e marcante na história do movimento operário dos Estados Unidos. Porém, o incêndio não é vinculado ao dia de luta das mulheres, nem à definição da data de sua comemoração. Essa versão, segundo Gianotti ${ }^{4}$, foi construída para reforçar a burocratização da União Soviética e o avanço do capitalismo ocidental em sua versão clássica americana, ou em sua versão social democrata Europeia, cada vez menos socialista, no período após as duas guerras mundiais.

(...) as duas guerras mundiais, a burocratização da União Soviética e o avanço do capitalismo ocidental na sua versão clássica americana, ou na sua versão social democrata europeia, cada vez menos

REVISTA GRIFOS - N. 34/34 - 2013 
socialista, não tinham interesse em comemorar o 8 de Março. Nos

países comunistas, após a $2^{\text {a }}$ Guerra Mundial, voltaram as comemorações do 8 de Março. Mas estas eram mais para louvar a política dos seus respectivos governos do que para encaminhar a luta pela total libertação da mulher. Nesse caldeirão cultural mundial, em Chicago, em 1968 e em Berkeley, em 69, se retoma, através de boletins e jornais feministas, a idéia do Dia Internacional da Mulher. Só que se esquece de que no começo do século, quando nasceu o Dia da Mulher, se acrescentava a qualificação de socialista. Este dia tinha caído no esquecimento, enterrado por sucessivas avalanches históricas (GIANOTTI, 2004, s/p).

Entre esses motivos e para esconder a luta socialista das mulheres cria-se o mito das 129 operárias queimadas, para González (2010),

No dia 08 de março de 1996, o jornal El mundo publicava um artigo que tinha como titulo "Aquele 08 de março... que nunca existiu”. $\mathrm{O}$ artigo afirmava que não existia nenhuma confirmação documentada do fato histórico que motivou o nascimento do Dia Internacional da Mulher, ao menos o que amplamente se acreditava ser a origem do 08 de março: o incêndio de uma fábrica têxtil de Nova Iorque ocorrido nesse dia, no ano de 1908, causado por seu proprietário que, diante da ocupação e declaração de greve de suas empregadas, decidiu por fogo na fabrica com elas dentro, causando a morte de um grande número delas (GONZÁLEZ, 2010, p. 21-22).

Conforme a mesma autora, outra versão que está sendo recuperada pelas feministas é de que o 08 de março nasceu da luta das mulheres socialistas. Para esta versão, essa data foi aprovada na segunda Conferência de Mulheres Socialistas em 1910, a partir da já existente comemoração de vários países, que acontecia em datas diferentes a cada ano, através de atividades organizadas pelas mulheres socialistas. Neste sentido, todos os países presentes na Conferência assumiram o compromisso de realizar atividades em prol das mulheres, porém sem definição de uma data em comum, tendo como orientação a reivindicação do direito ao voto. Essa proposta se manteve entre os anos de 1910 a 1920, sendo a partir deste momento estabelecida a data do dia 08 de março como símbolo da luta das mulheres, dando início à revolução de fevereiro na Rússia,

Foram às manifestações das mulheres na Rússia, no dia 8 de março de 1917 (dia 23 de fevereiro segundo o antigo calendário russo) que motivaram a escolha do Dia Internacional das Mulheres, al- 
guns anos depois. A confluência das comemorações do Dia Internacional das Mulheres com a greve das operárias têxteis e a revolta das mulheres com a escassez de alimentos foi o estopim da Revolução de fevereiro de 1917 na Rússia (FARIA, 2010, p. 13).

Faria (2010) também ressalta que o dia 08 de março foi escolhido para comemorar de forma unificada o Dia Internacional das Mulheres e para homenagear a ação das mulheres na história da Revolução Russa. A decisão dessa unificação se deu na Conferência das Mulheres Comunistas, coincidindo com o Congresso da Terceira Internacional, realizado em Moscou, em 1921.

As manifestações para inserir as questões das mulheres na sociedade se deram por diversas formas, na medida em que eram construídas estratégias de ações, que as envolviam na luta pelos seus direitos, pela libertação de todas as formas de opressão e para a conquista de uma sociedade socialista. Neste sentido, percebe-se, a partir das reflexões de tais autores, que o fato atribuído ao incêndio da fábrica ocupada por mulheres é significativo, entretanto, não contempla a totalidade de lutas empreendidas pelas mulheres.

$\mathrm{Na}$ contemporaneidade, os meios de comunicação, empresas e instituições retomam o Dia Internacional das Mulheres e o transformam em uma data comemorativa, na qual as mulheres recebem flores, homenagens, presentes. Neste sentido, o entendimento de que o lugar da mulher é cuidar da casa, ser rainha do lar, esposa e mãe dedicada é cada vez mais reforçado. Com isso, o capitalismo se fortalece ao inserir a comemoração do dia 08 de março no mercado. Ao atribuir um novo sentido à origem desta data, que nasceu da luta socialista, a sociedade capitalista desvirtua esse importante instrumento de luta pelos direitos das mulheres e da classe trabalhadora.

O Dia Internacional das Mulheres expressa uma história de luta e organização, e, portanto, deve ser compreendido como uma luta de classe das mulheres trabalhadoras, no reconhecimento e esforço das militantes socialistas em construir uma dinâmica de organização e de luta. Neste sentido, Faria (2010) argumenta que

Recuperar o histórico do Dia Internacional das Mulheres como parte da luta social, como inegável ponto de intersecção entre a luta das trabalhadoras, do movimento socialista e da luta feminista, evidencia o caráter político dessa comemoração e, ao mesmo tempo, retoma historicamente o esforço das militantes socialistas em construir uma dinâmica de organização e luta especifica das 
mulheres. A história evidencia a resistência - e mesmo o rechaço - de setores do movimento socialista à perspectiva de organização das mulheres, alicerçada na recorrente incompreensão do direito das mulheres à igualdade no mundo publico (ao trabalho e à participação política), contrastando com a realidade da sua presença no trabalho agrícola e no proletariado industrial, já fortemente marcado pela divisão sexual do trabalho. Em diversos setores a mão de obra feminina era mesmo majoritária. Difícil seria pensar na organização da luta revolucionária sem a participação das trabalhadoras (FARIA, 2010, p.12).

Esta reflexão nos remete à importância desta data como um dia de luta que tem por caráter político transformar a sociedade a partir dos ideais socialistas, criar condições para a emancipação das mulheres e garantir sua participação política nos espaços de decisão. Ao longo da história, as manifestações organizadas pelas mulheres eram construídas com muita sabedoria e astúcia, com diversas estratégias para colocar à sociedade suas questões.

Dentre as principais lutas se destacam, o direito ao voto, igualdade de salário para as mulheres, jornada de trabalho de 8 horas, licença e seguro obrigatório na maternidade e educação. Enfim, a luta contra o sistema explorador da burguesia com o intuito de construir uma sociedade socialista, se baseou na solidariedade internacional e fortaleceu a organização das mulheres trabalhadoras em torno de um mesmo objetivo.

É com esse pensamento de luta e organização que o MMC compreende o dia 08 de março, como uma data que marca a luta e a resistência das mulheres trabalhadoras.

\section{Movimento de Mulheres Camponesas e 08 de Março}

É importante ressaltar que o movimento de mulheres camponesas é fruto de uma trajetória política iniciada nos anos 80. A partir de então, o país vive uma nova fase, pois a população intensificou o processo de abertura democrática e ao mesmo tempo avançou a organização popular e sindical e a luta pelos direitos da classe trabalhadora.

A influencia da teologia da libertação, através de setores da Igreja Católica e Luterana que assumiram a opção pelos pobres, intensifica um trabalho de formação e organização popular nas Comunidades Eclesiais de Base (CEBs) e na Comissão Pastoral da Terra (CPT). (MMC, 2008, p. 09-10). 
No que se refere especificamente à luta dos movimentos sociais do campo no Brasil, a partir da década de 1960 houve uma grande mudança na forma de produção na agricultura, com a implantação da revolução verde como um modelo tecnológico que modifica a vida dos camponeses e das camponesas. Esse modelo, criado nos Estados Unidos, apresentou ao meio rural um pacote de mecanização, adubos químicos, sementes híbridas e agrotóxicos. Em Santa Catarina, a implantação desse pacote foi iniciada via atividades de assistência técnica através da ACARESC, com dias de campo, demonstrativos, festas e concursos organizados pelos Clubes $4 \mathrm{~S}$ e pelos clubes de mães.

O impacto da Revolução Verde neste contexto causam uma série de consequências para a agricultura, o endividamento nos bancos, baixo preço dos produtos, corte de subsídios agrícolas, êxodo rural e outros. É nesse contexto que o movimento de mulheres camponesas nasceu em Santa Catarina no início dos anos 1980, como uma organização específica das mulheres agricultoras.

Em diversos municípios as mulheres camponesas sentiam a necessidade de serem ouvidas e valorizadas. Reúnem-se e trocam idéias sobre a possibilidade de construir uma organização própria para enfrentar e superar suas dificuldades. No dia 01 de maio de 1983, em Nova Itaberaba, na época distrito de Chapecó, algumas mulheres passaram a dar organicidade a um grupo. A principal motivação para a participação das mulheres na luta era a oposição sindical. Mas elas também traziam presente questões referentes ao seu cotidiano de discriminação, exploração do trabalho, endividamento, preços baixos dos produtos, êxodo rural, entre outros. Todo este envolvimento dá origem aos primeiros alicerces de uma organização especifica e autônoma de mulheres camponesas (MMC, 2008, p. 09).

Esta organização constitui o Movimento de Mulheres Agricultoras (MMA) em Santa Catarina. No Brasil, vários movimentos autônomos de mulheres do campo surgiram simultaneamente e a partir dos anos 2000 sentiu-se a necessidade de consolidar um movimento autônomo de caráter nacional. Em 2004, em um Congresso Nacional, foi criado o MMC do Brasil (MMC, 2008).

Segundo o MMC (2008), o movimento autônomo de mulheres camponesas assume a missão de libertação das mulheres trabalhadoras que sofrem qualquer tipo de opressão 
e discriminação. Isso se concretiza nas lutas, na organização, na formação e na implantação de experiências de resistência popular, onde as mulheres sejam protagonistas de sua história. O MMC luta por uma sociedade baseada em novas relações sociais entre os seres humanos e na interação deles com a natureza. Sendo um dos primeiros movimentos autônomos de mulheres do campo no Brasil, o MMC se afirma com um caráter autônomo, de base e de classe, feminista, camponês e popular. Autônomo, porque são as mulheres que decidem os rumos do movimento, suas ações e estratégias. De base, porque são as mulheres do campo organizadas nas comunidades; de classe porque elas assumem a luta da classe trabalhadora; feminista por lutarem pelo direito das mulheres; camponês por assumirem a identidade de camponesas na luta por um projeto de agricultura camponesa agroecológica; popular porque assume um projeto popular.

O MMC em Santa Catarina compreende o dia 08 de março como um dia de luta desde sua origem, porém conforme tratado anteriormente, durante muito tempo esta data esteve associada à história do dia 08 de março de 1857, na cidade de Chicago, no qual 129 operárias foram queimadas vivas pelo patrão por exigirem melhores condições de trabalho. Somente a partir do dia 08 de março de 2009 é que o MMC começou a problematizar as origens desta data, elaborando textos nos quais referenda o surgimento do Dia Internacional da Mulher associado à luta socialista das mulheres.

Nesta direção, o MMC coloca em pauta a luta pela libertação das mulheres de todas as formas de exploração, para a transformação da sociedade. O MMC entende que esta libertação se dá por obra e protagonismo das mulheres e é nesse sentido que o 08 de março tem significado um dia de luta pelos seus direitos e da classe trabalhadora como um todo.

Desta forma, as mulheres camponesas que pertencem ao movimento, demarcaram ao longo dos anos o Dia Internacional da Mulher com diferentes ações para representar esse dia de luta e resistência. Neste sentido, na sequência buscarei ressaltar as principais bandeiras de lutas, as estratégias de organização e construção, os gritos de ordem que perpassam o dia 08 de março para o MMC.

A partir de pesquisas em materiais do MMC, percebe-se que as ações do movimento se pautam em torno das necessidades das mulheres, que além de sofrerem todo o impacto do novo 
5 Reflexões sintetizadas e elaboradas a partir de diversos materiais do $\mathrm{MMC} / \mathrm{SC}$, como folders e cartilhas elaboradas no período de 1991 a 2004. modelo de agricultura, que comprometeu fortemente a produção diversificada, a sabedoria popular sobre as sementes, o uso e manejo das plantas medicinais e da saúde, sofrem a imposição da padronização dos alimentos, a troca do suco de frutas por refrigerante, a nata pela margarina, o salame pela mortadela, padrões esses que cercearam seu direito e capacidade em decidir sobre o que produzir e investir na unidade de produção.

Nesse sentido, o movimento foi e tem sido uma ferramenta importante na tomada de consciência das mulheres que, através de encontros de formação e reuniões, debatiam a conjuntura e o que as mulheres precisavam fazer para mudar essa situação. Tais encontros e reuniões permitiram a elas perceber que possuíam direitos e que para garanti-los precisavam se organizar, estudar e juntas lutar para a conquista destes. (MMC, 2005).

A importância do movimento autônomo se concretiza na medida em que as mulheres conquistam a liberdade para discutir seus problemas e necessidades, pois até então, em espaços como sindicatos, por exemplo, o papel das mulheres era servir, não tendo a oportunidade de expor suas ideias, de votar e de decidir coletivamente as ações.

Nesta direção houve um forte apoio e incentivo do Bispo Dom José Gomes e dos debates nas CEBs, espaços onde as mulheres começam a se encontrar e discutir, e juntas perceberam as diversas bandeiras de luta que se fazem necessárias para mudar suas condições de vida: a retomada do projeto de agricultura camponesa agroecológico, a saúde, a documentação, o reconhecimento da profissão de agricultura, educação, entre outros.

Nesta trajetória, as mulheres perceberam que não tinham sequer o reconhecimento da profissão de trabalhadora rural. A reivindicação pelo reconhecimento da profissão foi fortemente debatida pelo movimento durante o dia 08 de março em vários municípios do Rio Grande do Sul, o que culminou no encontro estadual do dia 17 de outubro de 1985 em Porto Alegre, que reuniu 10.000 mulheres ${ }^{5}$.

A partir desta reivindicação, o movimento tem constituído suas bandeiras e se fortalecendo como MMA, sendo a luta central focada no reconhecimento da profissão de agricultora, o direito de ser associada e disputar a direção do sindicato, o direito a aposentadoria e outros.

O final da década de 1980 e início de 1990 foram marcados pela luta do direito à aposentadoria das mulheres aos 55 anos e 
dos homens aos 60 anos, auxílio maternidade, direito a trabalho e salário igual, igualdade jurídica entre o homem e a mulher. Em relação a esta questão, o movimento se manifesta ${ }^{6}$,

Estas são lutas conquistadas apenas no papel, pois estas leis não foram regulamentadas. Por isso nossa luta continua e estamos convocando todas as/os companheiras/os trabalhadoras/es rurais e urbanas/os para fazer parte da grande mobilização no dia 08 de março de 1989 onde vamos exigir das autoridades Competentes a Regulamentação da lei que trata da aposentadoria das trabalhadoras/os Rurais, do artigo 202 que garante a aposentadoria aos 60 anos para o homem e aos 55 anos para a mulher, e as demais conquistas. Vamos também denunciar a violência contra a mulher no trabalho e na sociedade.

À medida que a organização foi se fortalecendo, as mulheres perceberam que precisavam avançar ainda mais na conquista de direitos. Essa necessidade se expressa em diversos materiais produzidos pelo movimento, nos quais as mulheres camponesas se manifestam da seguinte forma "lutamos pela obtenção da documentação necessária para o pleno gozo da cidadania", pois até então não tinham documentos e eram consideradas "sombras de seus maridos".

A conquista da documentação neste primeiro momento era importante, pois permitia fazer uso de direitos como a profissionalização do trabalho das donas de casa, igualdade de oportunidades no mercado de trabalho nota fiscal de produtora as agricultoras, saúde e direitos reprodutivos, aposentadoria da mulher, salário maternidade, proteção à maternidade, creche para as filhas e os filhos menores, educação "diferenciada". Tais reivindicações e conquistas expressam uma causa tanto das mulheres trabalhadoras do campo quanto da cidade. Outra questão muito forte de denúncia era a violência que as mulheres sofriam, sendo que as mesmas entendiam que esse era um problema social que precisava ser resolvido. A Reforma Agrária também estava descrita em materiais pesquisados a partir de 1991, pois as mulheres entendiam que para permanecer produzindo no campo, era necessário ter acesso à terra para as camponesas e camponeses. Nesse período, a luta pela terra avançou no Brasil e em Santa Catarina, sendo que várias companheiras do movimento ajudaram a organizar as ocupações dos trabalhadores sem terra.
6 Folder elaborado para convidar as mulheres trabalhadoras à luta em 1989 (arquivo MMC/SC, caixa. 35). 
Em material datado de 1993 identificou-se reivindicações como saúde integral para a mulher, funcionamento dos conselhos municipais de saúde, garantia dos direitos conquistados na constituição, imediata regulamentação da Reforma Agrária, política agrícola e fim da violência contra as mulheres.

A partir de 1996 vários materiais foram elaborados, com o objetivo de preparar o dia 08 de março e orientar as mulheres a fazerem o estudo de um tema específico, conforme a conjuntura atual e a pauta de luta construída para cada ano. Esses estudos eram realizados nas comunidades junto aos grupos de base do movimento, onde eram debatidos aspectos da realidade vivida, das conquistas alcançadas e dos desafios para a continuidade da luta.

Um momento importante nesta trajetória foi o registro do $1^{\circ}$ Acampamento Nacional de Mulheres Trabalhadoras Rurais, realizado em Brasília, em 2000, por ocasião dos 500 anos do Brasil. Neste acampamento as mulheres camponesas juntamente com outros atores sociais se manifestaram contra os 500 anos de dominação, através da palavra de ordem "Aqui são outros 500".

Mais de três mil mulheres que vivem de seu trabalho na roça, vindas em caravanas, de todos os estados, acamparam em Brasília, entre os dias 13 e 17 de março de 2000, como sinal vivo de LUTA, CORAGEM e RESISTÊNCIA do povo brasileiro que não agüenta mais a dominação que nos foi imposta pelas elites dominantes, desde que os portugueses chegaram em 1500. Com o acampamento damos o inicio a um conjunto de lutas populares no Brasil que foram sucedidas pela mobilização dos índios, dos trabalhadores sem terra, dos pequenos agricultores e do Levante do conjunto dos trabalhadores(as) rurais, bem como pelo processo do Plebiscito da Dívida Externa. É o povo Brasileiro lutando em busca da libertação (ANMTR, 2003, p.12).

O conteúdo expresso neste material tinha o objetivo de preparar o dia 08 de março do ano subsequente, sendo que os principais debates realizados durante os encontros preparatórios que antecederam ao acampamento foram: "O projeto dos poderosos e as consequências na vida das mulheres trabalhadoras rurais", "As mulheres e o Projeto Popular", "As mulheres e o trabalho de base", "Preparando o nosso acampamento".

Novamente, no Dia 08 de Março de 2001, no espírito de UNIDADE POPULAR, de FORÇA, de GARRA e CORAGEM misturadas com a TERNURA e ESPERANÇA FEMININA, 
iremos saborear os sinais de vida e solidariedade que brotam da organização popular. Iremos também denunciar e enfrentar a dureza das marcas da dor da opressão, da exploração e discriminação que FHC e seus aliados estão impondo sobre a vida de milhões de Brasileiros, especialmente dos trabalhadores (as) da cidade e dos (as) que vivem da terra (ANMTR, 2003, p.13).

Os anos de 2000 a 2002 são marcados por acampamentos e debates que visam a denúncia do modelo de agricultura vigente, tendo em vista a proposta de um novo Projeto de Agricultura defendido pelo movimento, baseado nos princípios da agroecologia. Em 2003, por ocasião da preparação do dia 08 de março, o movimento debateu nos encontros de grupo de base as seguintes temáticas: o 08 de março, Dia Internacional da Mulher Trabalhadora, dia de luta resistência e compromisso, o projeto de agricultura e as relações de gênero e classe na roça, principais lutas das mulheres trabalhadoras rurais do Brasil: Previdência e Saúde, Preparando o Dia Internacional - 08 de março/2003.

É através desta trajetória de debates e de reflexões que as mulheres reafirmam o dia 08 de março como um dia de luta, pensam e propõem um projeto de agricultura baseado nos princípios da agroecologia, construindo novas relações de gênero com os companheiros e assumindo a luta de classe no campo.

O Brasil é o $2^{\circ}$ país do mundo em concentração de terra, impedindo que 4,8 milhões de trabalhadoras (es) tenham um pedaço de chão para plantar. Junto com a concentração de terra, a do poder e da renda no meio rural, impedem uma vida digna a quem vive na roça, agravando o êxodo rural e as desigualdades no campo e na cidade. (ANMTR, 2003, p. 15).

Nesta direção de lutas por um novo modelo de agricultura, o movimento mais amplo de trabalhadores rurais denuncia os resultados da ofensiva histórica dos capitais multinacionais para a agricultura, ao afirmar que

Para os quatro principais ramos, ou seja, produção de fármacos (medicamentos) de agrotóxicos, de fertilizantes químicos e de sementes: as 10 maiores empresas de cada ramo controlam $84 \%$ do mercado mundial $48 \%$ do mercado mundial farmacêutico e $30 \%$ do mercado mundial de sementes. (ANMTR, 2003, p. 15). 
O movimento propõe um projeto de agricultura camponesa agroecológica como contraponto a esse modelo, reforçando a luta por uma agricultura sustentável, agroecológica, equilibrada e diversificada, na qual a produção seja voltada para a auto-sustentação da família, garantindo a permanência das/os agricultoras/es no campo.

Em 2004, o dia 08 de março constituiu um marco histórico, pois foi nesse momento que se consolidou o MMC no Brasil. Foi apresentado em documento elaborado pelo movimento, que tem por objetivo servir de instrumento para estudo e preparação ao Congresso Nacional do Movimento de Mulheres Camponesas, a história de luta das mulheres na sociedade, o motivo de organizar o movimento autônomo de mulheres e as lutas que reafirmam a existência do movimento, refletindo sobre os elementos fundamentais para a existência e continuidade do MMC em seu trabalho de base e sustentação de toda luta popular.

A história de organização das mulheres camponesas tem nos ensinado que somente com a luta organizada, expressada nos acampamentos, ações, encontrões, marchas, atos públicos (...) aumentamos nossa força e fomos forjando e conquistando nossos direitos: reconhecimento da profissão, aposentadoria, salário maternidade, saúde (...) nos ensina, também, que devemos estar "vigilantes e alertas" para a garantia dessas conquistas. Isto nos faz sentir sempre em movimento, sempre fazendo nossa história. (MMC/Cartilha de preparação ao Congresso Nacional do Movimento de Mulheres Camponesas, 2003).

O movimento neste dia 08 de março reafirmou a luta para a vida digna, a construção de novas relações de igualdade entre homens e mulheres, o trabalho na perspectiva das mulheres camponesas, a construção da própria história, a conquista de direitos e a importância da participação das mulheres nas decisões da família e na sociedade.

A tomada de consciência e a libertação das mulheres são frutos de um processo que exige dedicação, garra, sacrifício, amor, responsabilidade e perseverança, para lutar contra todas as formas de violência e discriminação sobre a mulher.Tais elementos quando em prática e em relação a tal luta, constroem uma sociedade socialista, ao recusarem o neoliberalismo, o capitalismo e o patriarcado.

Para reafirmar o que seria debatido e referendado no Congresso Nacional, o movimento organizou e construiu debates 
nos grupos de base, viabilizou processos de formação, construiu

alianças com outros movimentos e organizações que defendem o mesmo projeto e destacou suas principais bandeiras de luta.

Combater o modelo de sociedade Neoliberal e o modelo de agricultura atual; Lutar pela garantia dos direitos previdenciários; Lutar em defesa do ambiente como um todo; Lutar por um novo projeto de agricultura agroecológica; Campanha de documentação; Lutar pelo não pagamento da divida externa; Lutar pelo rompimento dos acordos com o FMI (Fundo Monetário Internacional) e o Banco Mundial; Combater incansavelmente as políticas das multinacionais; Lutar por uma política agrícola voltada para o novo modelo de agricultura com crédito de investimento, custeio subsidiado, preços justos, seguro com valorização da agricultura local; Lutar por saúde pública e de qualidade para todos. Construir junto com os outros movimentos sociais a luta contra a implantação da Alca (MMC, 2003, p.16-17).

A luta pelos direitos trouxe e ainda traz importantes avanços na melhoria de vida das mulheres e de suas famílias, pois possibilita às mulheres saírem de casa e a romperem com a cultura patriarcal, a partir do momento em que conseguem dividir as tarefas da casa. A história dessa luta tem resultado na construção de novas relações sociais de gênero e de classe, bem como, na luta pela conquista dos direitos, buscando construir relações de justiça e igualdade, que são bases para um projeto popular para o Brasil.

O dia 08 de março de 2006 marca uma nova forma de fazer a luta ao denunciar o avanço dos projetos do capital no campo que destroem a vida local, expulsam camponesas e camponeses e causam um grande impacto ambiental, cultural e social. No âmbito nacional e internacional, as mulheres revelam a questão do deserto verde, com a ação na Aracruz Celulose em Barra do Ribeiro no Rio Grande do Sul.

Antes de se referir a este fato, é necessário entender que as mulheres organizaram essa ação de enfrentamento ao capital pois este muda a vida das pessoas e do local, no qual o agronegócio se instala através da produção de monocultivos.

Historicamente, o Brasil teve seus bens naturais explorados para fornecer matéria prima para as elites desde a invasão de Portugal, seja através do pau-brasil, ouro, café, ou mais tarde através da soja e do extrativismo. Atualmente a monocultura é imposta na agricultura pelo pacote do agronegócio, sendo que o avanço acontece através do plantio de árvores exóticas como pínus, 
acácias e, principalmente, o eucalipto. As principais empresas do agronegócios são Aracruz Celulose, Votorantim Celulose e Papel, Stora Enzo e Veracel. Muitas vezes essas empresas são apoiadas pelos governos e se instalam nos países para explorar as terras e a água na produção de celulose (PALUDO, 2009).

Segundo a mesma autora, a Aracruz Celulose se instalou há 40 anos no Norte do Espírito Santo, tendo como consequência a destruição de 1965 comunidades e cerca de 8.700 famílias. Quilombolas e povos originários venderam suas terras com a promessa de oferta de trabalho e renda por tal empresa para todos. Porém, com a mecanização da indústria, a mão de obra altamente qualificada era exigida e como a população da região possuía uma escolaridade baixa, foram excluídos de determinados cargos.

O despojo de seus territórios também inviabiliza a produção de alimentos e a criação de animais, sendo que os poucos que resistiam eram ilhados pelos eucaliptos da empresa, sobrevivendo do plantio de mandioca para fazer farinha e da cana para fazer melado. Utilizavam também restos de madeira e eucalipto para produzir carvão vegetal, além de outras pequenas produções, como frutas e verduras, no próprio quintal de casa, onde restava o mínimo de terra que ainda conseguiram garantir. Restaram-lhes os ofícios mais degradantes, como carregar tonéis com herbicidas e agrotóxicos, que são usados no cultivo de eucalipto. Para facilitar a colheita, em média são jogados 250 mil litros de herbicidas por dia nas plantações de eucalipto. Um dos venenos usados é o Tordon, que além de ser ilegal é altamente cancerígeno e causa muitas doenças genéticas.

De acordo com Paludo (2009), em 2005 essas empresas começam a adquirir grandes extensões de terra no Rio Grande do Sul, investindo 50 milhões. Já em 2006, a empresa estimava investir 250 milhões em florestamento, entre a compra de terras, instalação de viveiros e plantio de eucalipto.

No mesmo livro encontram-se vários dados que retratam as consequências dessa forma de produção. As mulheres camponesas da Via Campesina percebem os impactos que causariam o avanço dessas empresas, tais como problemas ambientais, concentração da terra - que prejudicaria a Reforma Agrária, fortalecimento do modelo de concentração de terra, de capital e de renda, e fortalecimento do modelo exportador - pois estes são isentos de contribuir com os cofres públicos dos municípios e do estado. 
Além de a empresa não gerar empregos, ela expulsa as populações, massacra as culturas locais, inviabiliza o plantio consorciado, aumenta a prostituição e concentra as tecnologias em grupos transnacionais. Munidas dessas consequências, as mulheres camponesas da Via Campesina realizam a ação contra a Aracruz Celulose na luta pela vida.

A ação em defesa da vida, contra o monocultivo de celulose, aconteceu na madrugada do 08 de março de 2006, em Barra do Ribeiro, RS. Foi algo diferente, porque em se tratando da envergadura que essa luta adquiriu e do espaço que obteve junto a mídia, julga-se que o impacto maior foi por ter sido empreendida por mulheres! Do ponto de vista da sociedade patriarcal, que estabelece papeis e funções para as mulheres e homens, entre violência e docilidade imbecilidade foi de fato assustador. Algo que a história mais atual, pelo que consta até então, não havia registrado. A data coincidiu com a $2^{\text {a }}$ Conferencia Internacional da $\mathrm{FAO}^{7}$, que estava acontecendo, de 07 a 10 de março, na $\mathrm{PUC}^{8}$, em Porto Alegre. Foi uma ocasião propicia para denunciar a exploração das empresas transnacionais da celulose, assim como denunciar que a Reforma Agrária andou a passos lentos, quase estagnados, no atual governo (PALUDO, 2009, p.153).

7 FAO - Organização das Nações Unidas para a Agricultura e Alimentação.

8 PUC - Pontifícia Universidade Católica do Rio Grande do Sul.

A ação se deu através da articulação, dos debates e reuniões das mulheres da Via Campesina.

Pode se dizer que a relação entre as mulheres camponesas foi tecida ao longo de anos, com idas e vindas, conflitos e descobertas. As relações entre as mulheres dos diferentes movimentos e da pastoral foi cuidadosamente mantida, politicamente alimentada e afetivamente vivida. As articulações realizadas para a ação do 08 de março de 2006 vinham sendo construídas a partir da articulação das Mulheres da Via Campesina do Rio Grande do Sul, desde 2005, enquanto se observava a necessidade de unidade em vista de um inimigo forte e poderoso, que parecia vir esmagando os empobrecidos como um rolo compressor (PALUDO, 2009, p. 153).

As mulheres da Via Campesina, principalmente do MMC de Santa Catarina, participaram da ação no dia 08 de março de 2006, reunindo mais de 400 mulheres. A ação corajosa das mulheres marca profundamente a luta de classes no país. Em contraponto ao dia 08 de março de 2006, no qual as mulheres da Via Campesina fizeram a ação de denúncia do avanço dos monocultivos de eucalipto para celulose o movimento, foi lançado 
no dia 08 de março de 2007, a Campanha Nacional pela Produção de Alimentos Saudáveis em diversos estados do Brasil, inclusive em Santa Catarina.

A campanha nacional pela Produção de Alimentos Saudáveis é um instrumento, uma forma, um jeito de discutir e propor, a partir das mulheres organizadas, outra proposta de agricultura, de relações pessoais e sociais, e de relação com o meio ambiente. A Campanha quer tornar visível o potencial produtivo da agricultura camponesa e evidenciar o trabalho exercido pelas mulheres neste espaço. Também se propõe a ser um espaço de dialogo com o meio urbano no que se refere à produção e consumo de alimentos (MMC, folder do 08 de março de 2010).

Em Santa Catarina, além do lançamento dessa campanha, o movimento realizou em Florianópolis o debate sobre a importância da alimentação saudável, com mulheres trabalhadoras urbanas de diversas comunidades. Além disso, foi realizada a doação de alimentos produzidos pelas mulheres camponesas.

Simultaneamente à campanha, o MMC entregou uma pauta de negociações ao governo do estado com o objetivo de viabilizar a campanha nas unidades de produção, com infraestrutura para hortas, hortos de plantas medicinais, viveiros, cisternas, capacitação na linha da agroecologia para a produção de alimentos e para o uso e manejo das plantas medicinais. Foi realizado ainda um ato contra o imperialismo e sua imposição sobre os demais países.

Entre 2008 e 2013 o MMC continuou pensando o 08 de março como um dia de luta, de denúncia e reivindicação, e nesse sentido foram realizadas ações que pautaram o avanço do agronegócio no campo, seja, através dos monocultivos de pinus e eucalipto, seja, através das sementes transgênicas e agrotóxicos, a questão ambiental e dependência das camponesas e camponeses ao pacote químico imposto pelo modelo agrícola.

$\mathrm{Na}$ pauta do MMC desses anos, se destaca a produção de alimentos saudáveis com infraestrutura subsidiada pelo governo, educação, saúde pública e de qualidade, creches, aposentadoria para as donas de casa, fim da violência contra as mulheres e a classe trabalhadora, novo modelo energético, a questão ambiental, entre outros. As atividades em Santa Catarina aconteciam em conjunto com as mulheres da Via Campesina, com movimentos de mulheres trabalhadoras urbanas e a partir da articulação com sindicatos. 
Além da denúncia e da reivindicação o movimento traz presente para a sociedade a proposta da agricultura camponesa baseada na agroecologia como garantia de vida, sustentabilidade do planeta, através da recuperação e produção de sementes, a produção de alimentos saudáveis, plantas medicinais, viveiros de mudas nativas, o cuidado com a terra, a água e a biodiversidade como um todo.

As ações se davam através de marchas, fechamento de bancos, trancamento de trevos, acampamentos, atos em frente às empresas que representam o capital transnacional, ora aconteciam em Brasília, ora na capital dos estados, ora nas diversas regiões, e traziam sempre presentes a luta e a pauta das mulheres na transformação da sociedade.

Nos materiais pesquisados, encontram-se diversos gritos de ordem sobre a temática e a problemática abordada, como também gritos construídos no conjunto da Via Campesina, entre os quais destaco: "Mulheres da Roça a Previdência é Nossa", "Nós não queremos favores, nossa história a gente faz", "Mulheres organizadas, jamais serão pisadas", "Fortalecer a luta, em defesa da vida. Todos os dias", "Mulher camponesa, produzindo alimentos saudáveis, construindo libertação", "Mulher organizada, sociedade transformada", "Se o campo e a cidade se unir, a burguesia não vai resistir", "Mulher, água e energia não são mercadorias", "Sem Feminismo não há Socialismo”. Percebe-se a partir das leituras que todas as ações foram baseadas nos princípios e valores que o MMC tem construído ao longo dos seus 30 anos em Santa Catarina e nos 9 anos como um movimento nacional.

$\mathrm{O}$ resultado de todo o trabalho do movimento não beneficia somente as militantes, mas a população em geral, pois a aposentadoria, salário maternidade, SUS, auxílio doença, auxílio acidente de trabalho, auxílio invalidez, produção de alimentos saudáveis através da valorização da agricultura agroecológica e o reconhecimento da profissão de agricultora são conquistas de muita luta que têm melhorado a condição de vida de muitas pessoas.

\section{Considerações finais}

Ao longo da realização desta reflexão identifica-se presente a luta e o empenho das mulheres por sua emancipação e para a transformação da sociedade. A base desta luta é voltada para a construção do socialismo e se entende que este só se acontecerá 
mediante a presença firme das mulheres. Tal pensamento tem base em diversos fatos históricos relatados aqui, nos quais as mulheres tiveram um papel fundamental, possibilitando com sua astúcia e criatividade grandes conquistas pelos direitos para a classe trabalhadora, através das ações de denúncia da violência do modelo capitalista e patriarcal no campo e na cidade.

O dia 08 de março traz uma simbologia carregada de luta e resistência das mulheres frente à opressão e exploração em que viviam, representando um dia de luta e resistência das mulheres trabalhadoras do mundo e que deve ser reconhecido pela sociedade como tal. Neste sentido, é importante ressaltar a desconstrução que tem sido realizada em torno da desvirtuação desta data, dia em que as mulheres recebem, flores e homenagens, o que reforça o papel da mulher como rainha do lar, dona de casa, servidora de bem estar da família.

As mulheres do campo são motivadas por essa história de luta, pois esta tem resultado na construção de novas relações sociais de gênero e de classe. É através da luta pela conquista de direitos que o movimento busca construir relações de justiça e igualdade, base para um projeto popular para o Brasil e quiçá para o mundo.

O material usado para retratar o dia 08 de março no MMC está arquivado na biblioteca no Centro de Formação Maria Rosa em Chapecó, Santa Catarina, porém vários deles não contêm o ano de produção, o que dificulta a organização da bibliografia, aspecto que deve ser melhorado no movimento.

Neste sentido, para esta análise destaca-se a importância do material produzido pelo movimento como cartilhas, folders, panfletos utilizados nos encontros de formação nos grupos de base, além da panfletagem de rua, e diversos programas de rádio que as mulheres realizaram para ocupar espaços na mídia local, enfatizando as ações realizadas no dia Internacional da Mulher. Destacam-se também as propostas de celebração realizadas nos cultos e missas em datas próximas ao dia 08 de março, onde foram arrecadados recursos para deslocamento e despesas das atividades construídas.

Por fim, destaca-se que a luta pela emancipação das mulheres e da classe trabalhadora é fundamental para a construção de uma sociedade baseada em valores feministas e socialistas a serem conquistados, tendo como base uma luta de forma organizada e coletiva. 


\section{Referências}

ANMTR - ARTICULAÇÃO DE MULHERES TRABALHADORAS RURAIS. Em luta pelo Dia Internacional da Mulher (Cartilha para debater em grupos de mulheres em preparação a Mobilização Nacional de Mulheres trabalhadoras Rurais - 05 a 09 de março de 2001). S.1: s.e, 2001.

ANMTR - ARTICULAÇÃO DE MULHERES TRABALHADORAS RURAIS. Dia de Luta e Resistência e Compromisso (Cartilha para estudo e debates nos grupos de mulheres Trabalhadoras Rurais em preparação ao Dia Internacional da Mulher Trabalhadora - 08 de março de 2003). S.1: s.e, 2003.

GEBARA, Ivone. Cultura e relações de gênero. São Paulo: Cepis, 2002.

GIANNOTTI, Vito. Memória - 8 de Março. O Dia da Mulher nasceu das mulheres socialistas, 8 de março de 2004. Disponível em: <http. www. piratininga.org.br> Acesso em: 02 mar. 2010.

FARIA, Nalu. Apresentação. In: GONZÁLEZ, Ana Isabel Álvarez. As origens e a comemoração do Dia Internacional das Mulheres. São Paulo: Expressão Popular; SOF, 2010.

GONZÁLEZ, Ana Isabel Álvarez. As origens e a comemoração do Dia Internacional das Mulheres. São Paulo: Expressão Popular; SOF, 2010.

MMC. MOVIMENTO DE MULHERES CAMPONESAS - BRASIL, Congresso Nacional do Movimento de Mulheres Camponesas (Cartilha de preparação). S.1: s.e, 2003.

MMC. MOVIMENTO DE MULHERES CAMPONESAS EM SANTA CATARINA. Produção de sementes crioulas de hortaliças: as práticas de recuperação, produção e melhoramento de sementes de hortaliças do Movimento de Mulheres Camponesas em Santa Catarina MMC/SC. Chapecó: Estampa, 2005.

MMC. MOVIMENTO DE MULHERES CAMPONESAS. 08 de março. Dia Internacional da Mulher, Folder, S/l: s.e, 2010.

MMC. MOVIMENTO DE MULHERES CAMPONESAS EM SANTA CATARINA: Uma História de Organização, Lutas e Conquistas, Chapecó: Gráfica Rota, 2008. 
PALUDO, Conceição (Org.). Mulheres Resistência e Luta em Defesa da Vida. São Leopoldo: CEBI, 2009. 171 p.

SOF - SEMPREVIVA ORGANIZAÇÃO FEMINISTA. 8 de março. Dia Internacional da Mulher: em busca da memória perdida. Disponível em: <http://www.sof.org.br>. Acesso em: 17 fev. 2010.

TOLEDO, Cecília. Mulheres: o gênero nos une, a classe nos separa. Cadernos Marxistas. São Paulo: Xamã, 2001.

\title{
PEASANT WOMEN AND MARCH $8^{\text {TH }}$ IN CLASS STRUGGLE
}

\begin{abstract}
This paper presents a study on the origin and on the importance of March $8^{\text {th }}$, as an international date of female workers' struggle, in a perspective of class and gender. It presents a reflection upon women's actions, specially the peasants of the Peasant Women Movement, with the aim at recording elements that show what the peasants do on this date, thinking it as a day of resistance and bringing the participation of them in this process. The methodology used in it was participant research, through instruments of observation, documents and bibliography analyses, besides the author's insertion and participation on the movement.
\end{abstract}

Keywords: Peasant Women Movement. March $8^{\text {th. }}$. Class Struggle.

REVISTA GRIFOS - N. 34/34 - 2013 